\title{
Families Face Pandemic - A Review of Psychological Suggestions and Empirical Findings Regarding the Covid-19 Pandemic
}

\author{
Krisztina Törő \\ Gábor Csikós
}

Károli Gáspár University of the Reformed Church in Hungary Psychology Institute

\section{Abstract}

Aims. Even though child psychology researches related to a pandemic are extensive, the knowledge of practitioners about interventions and practices is still very limited. The complete novelty of such an epidemic situation in Europe, the diversity of terminology and methods are factors that make results hard to interpret. Therefore, the current study aims to give an overview of the psychological literature of the family aspects of the Covid-19 pandemic. Methods. A search was executed in four databases (Science Direct, Medline, Scopus, Google Scholar) using the following keywords: pandemic, Covid 19, family, children, adolescents, anxiety, depression. Our review focuses only on English language literature. Results. The majority of the articles focus on non-pathological phenomena and draws attention to the behavior of healthy populations (increase in internet use, the decline of concentration). Methods were dominated by online surveys. These surveys were mainly constructed ad-hoc and they preferred to address parents. Direct child investigations are underrepresented, but several suggestions were formulated for their optimal functioning. Conclusion:. Researches focusing on psychopathology emphasize the growth in the prevalence of disorders. However, other researches are needed to explore the psychodynamics of the pandemic on the family level. Our study aimed to contribute to the field by summarizing the main findings, suggestions, and interventions hoping that it might be a useful tool for practitioners and reduce the territory of the unknown.

Keywords: Pandemic, COVID 19, anxiety, depression, psychology, families, children

\section{Introduction}

Experts formulated suggestions at the very beginning of the coronavirus pandemic. These recommendations focused on efficient coping with the psychological 
challenges of the global epidemic. Notwithstanding the absence of such an epidemic in Europe these suggestions were created on a practical basis using the lessons of former Asian (SARS-1) or African (Ebola) epidemics. However, regional differences cannot be neglected that might be shaped by both former experiences (e.g. Singapore; Ho et al 2020) and cultural patterns in obeying rules.

The current coronavirus pandemic is not only a health issue. There are also significant effects on social and economic processes that heavily influence the daily life of even the smallest units of society, the families, and especially children. (Prime et al 2020) Cognitive maturity, personal characteristics, coping mechanisms, and resilience have a great impact on the child's psychological responses, but the interactions within the family should be also taken into consideration. (Parsons 2020)

The long-term effects of the pandemic are unknown and there is only a small amount of research even on the normal population (Lee 2020) this review aims to 1) collect the suggestions made by experts for effective coping with the current challenges, and to 2 ) summarize the main findings on families.

\section{Recommendations:}

Possible factors that carry risks for adolescents were formulated at the very early phase of the pandemic. At that time little was known about the pandemic but previous experiences of natural catastrophes (see: e.g. Pisano et al 2020) or local epidemics (e.g. Remmeswaal - Murris, 2011) could be used.

The effects of the suddenly-imposed lockdown and especially the closure of schools reshape everyday life for teenagers. Missing daily routine and live peerrelations, the unpredictability due to the abrupt of (university entrance) exams, or the extra burdens of online education could turn to be the pivotal stressors for children. (Sharma et al 2020; Dubey et al 2020, Ghosh et al 2020) Experts agreed that the greatest difficulty for the children would be sudden student life changes due to school closures. (Sharma et al 2020) Some even labeled this as "disruptive exogenous shock" (Huebener et al 2020). Furthermore, the adherence to social distancing rules might be challenging for the young for their high need for social connection, their heightened sensitivity to peer influence and risk-taking. (Andrews et al 2020). Excessive social media use also contains possible dangers for adolescents (Sharma et al, 2020) as the messages of the media influences their fears, and inmiddle term it might contribute to posttraumatic stress syndrome (PTSD) or phobias. So, not surprisingly besides pandemic researches also mention infodemic as a risk towards (mental) health. (Dubey et al 2020)

Recommendations drew attention to dynamics within the family. Children's emotion and cognitive regulation system are more vulnerable than adult's, so they might display impatience and annoyance, which may cause them suffering from physical and mental violence by overwhelmed parents. (Dubey et al 2020, Ghosh 2020) 
Intensified workload and fear of uncertainty might also hinder the parents' effective coping. (David et al 2020) Stressful family members can create a distressing family atmosphere that exposes children to secondary traumas. (Zhou et al 2020)

Plus, there are certain risk groups within the adolescent/children population who face greater challenges than their peers.

Ethnic minorities, refugees, and other marginalized groups within the society (Prime et al 2020, Ghosh et al 2020)

Institutionalized children. The deinstitutionalization of the children raises the risk of contagion. However, on the other hand, restricting the visits could reduce social support and makes harder the coping with stress (Goldman et al 2020)

Children with disabilities, including intellectual disabilities, (Ghosh et al 2020) autism and mental health disorders. For those who battle with depression, a daily routine is particularly important that might be disturbed by sudden life changes related to the pandemic. (Lee 2020)

Children of health care workers (Ghosh et al 2020; Dubey et al 2020) whose parents face a higher chance for contagion.

People diagnosed with Covid-19. (Dubey et al 2020) Quarantine increases the prevalence of post-traumatic stress syndrome and in long term, it also raises the occurrence of psychosis or suicide in adulthood. (Liu et al 2020)

For getting the full picture some other approaches are worth mentioning which focused on the possible positive effects of the pandemics. Inspired by positive psychology these suggestions highlighted that increased proximity within the family provides opportunities for promoting positive relationships by engaging in collaborative activities. Plus, adolescents may find themselves to be experts of the household technology expert that might raise their self-esteem and agency. (Dvorsky et al, 2020; Bruining et al 2020) However, these suggestions represent a minority compared to those that emphasize risks and threats.

\section{Suggestions}

Suggestions concentrated on 1) children/adolescents or 2) parents and family and finally, on 3) broader social context.

Recommendations focusing on adolescents generally highlight the importance of daily routine (Lee et al 2020, Parsons et al 2020) and a sufficient amount of sleep and physical activity. (Király et al 2020, Davis et al 2020). Coping with a stressful situation might be facilitated by information acquiring and the use of stress-reducing techniques. (Király et al 2020, Zhou et al 2020).

Another group of suggestions focuses on the family as a microsystem. This draws attention to the value of maintaining communication among family members (Király 
et al 2020). Family can function as a buffer for children regarding negative impacts. Family members might perceive the unpredictable events as threatening that promote anxiety. But, speaking openly about their feelings and thoughts can reduce stress effectively. (Dalton et al 2020) However, stress raises the prevalence of authoritative parenting or even domestic violence which hinders this type of communication. (Usher et al 2020; Cambell 2020; Prime et al 2020) Parents can reduce the stress of their children by 1 ) looking after their own mental wellbeing 2) providing age-appropriate information 3) reducing exposure to news and social media related to Covid-19 4) maintaining routines 5) involving children in a family plan to mitigate risk and promote mental and social wellbeing (Parsons 2020)

Parents also function as role models for the children (Király et al 2020) The parental experiences and perceived stress can raise the stress of their children due to secondary traumatization. For that reason, it seems important to provide support for parents in managing stress. (Zhou et al 2020,

In a broader context, the importance of social experiences should be also mentioned. Peer-influence is strong among adolescents and this can be even useful in promoting risk-avoiding behavior. It would be beneficial to involve teenagers in health campaigns for they convince their peers more effectively in e.g. prosocial behavior or physical activity. (Andrews et al 2020; Davis et al 2020) Experts also highlight the responsibility of the whole society. The Childcare system, school, and other institutions of the social sector should also provide psychological help both for children and adults who work with families (including teacher and child care workers) Teachers and parents should be trained not only in improving their selfhelp skills but also in detecting early signs of risks and disorders among children. (Liu et al 2020) There is also an urgent need for a supporting network that can concentrate on the families as wholes. (Goldman et al 2020; Zhou et al 2020)

\section{Empirical findings}

In the following, those researches are collected that was focusing on how the life of children/adolescents affected by the pandemic. Researches could acquire data by

(1) investigating the children/adolescents themselves

(2) asking parents about the psychological status of their children

(3) investigation of the family as a microsystem

(1) Studies examining adolescents directly

In accordance with the expectations formulated by the expert previously the greatest challenge for children was the school closures. Over $90 \%$ of enrolled learners worldwide were out of education (Lee 2020; Ellis et al 2020) First findings of Chinese research on a sample of 1210 persons pointed students as members of a risk group due to experiencing a high level of psychological distress. (Ho et al 2020) As in many 
countries, university entrance exams were postponed late adolescents faced a lot of uncertainty. According to a poll by a student counseling group in Hong Kong one-fifth of the 757 candidates said their stress levels were at a maximum 10 out of 10 . In the United Kingdom, 83\% of the participants in a survey that included young people up to 25 years with mental illness history reported the worsening of their living conditions due to the pandemic. (Lee 2020)

Qualitative research was carried out in Spanish research that highlighted the importance of feeling guilt which can be a marker for post-traumatic stress symptoms. This study detected boredom, anger, tiredness, and loneliness among children on one hand, but also found several signs of positive sentiments including joy and happiness for the increased amount of shared activities by the family members. So, it should be noted that families were doing great work in creating safe and pleasant spaces for the youngest. (Idoiaga et al 2020) For the descriptive statistics of the researches mentioned here, see Table 1.

\begin{tabular}{|c|c|c|}
\hline $\begin{array}{l}\text { sample } \\
\mathrm{n}=228 \\
\text { Mage }=7.14 \pm 2.57\end{array}$ & $\begin{array}{l}\text { surveys } \\
\text { free association exercise }\end{array}$ & $\begin{array}{l}\text { source } \\
\text { Idoiaga et al 2020) }\end{array}$ \\
\hline $\begin{array}{l}n=1,054 \\
\text { Mage }=16.68 \pm 0.78\end{array}$ & $\begin{array}{l}\text { Covid-19 Test, Social Media Use, } \\
\text { Time in daily activities, Brief } \\
\text { Symptom Inventory (Depression), } \\
\text { Loneliness Scale, Physical Activity }\end{array}$ & Ellis et al 2020 \\
\hline $\begin{array}{l}\mathrm{N} 1=86, \mathrm{~N} 2=196, \mathrm{~N} 3= \\
54 \\
\text { undergraduate } \\
\text { students }\end{array}$ & $\begin{array}{l}\text { perceived stress scale, GCES } \\
\text { Depression Scale, Anxiety Disorder } \\
7 \text { Scale, UCLA Loneliness Scale, }\end{array}$ & Elmer et al 2020 \\
\hline$n=683$ & Patient-Reported & Oosterhoff et al \\
\hline Mage $=16.35 \pm 1.13$ & $\begin{array}{l}\text { Measurement Information System } \\
\text { (PROMIS)anxiety scale; } \\
\text { Interpersonal Needs Questionnaire }\end{array}$ & 2020 \\
\hline
\end{tabular}

Table 1: Descriptive statistics of some major research with a focus on the experiences of the adolescents

Focusing on youth in their middle - or late adolescence research found the virus, the schooling, and peer relationships as the greatest subject of concern in Canada. Those who spend more time on social media reported a higher level of loneliness and depression. Physical activity and family time correlated with a lower level of depression while connecting to friends virtually raised its prevalence. (Ellis et al 2020)

The surveying of undergraduate students revealed that friendship networks remained relatively stable, while informational and emotional support nominations 
slightly increased. They reported that personal problems affected them more than usual. Students felt more socially isolated, and they were more worried about family and friends, the economy, and their future carrier. Surprisingly, they were only slightly more worried about their own health or their financial situation. (Elmer et al 2020) Taking personal responsibility for others proved to be a center motivation for adolescents in other researches too. Teenagers most commonly named prosocial motivation in their engagement towards social distancing. Social responsibility $(78,1 \%)$, not wanting others to get sick $(77,9 \%)$ were the core elements in their responses. Not wanting to personally get sick remained underrepresented $(57,8 \%)$ comparing to prosocial reasons. (Oosterhoff et al 2020)

\section{(2) Research examing children through parental perception}

Experts in their recommendation highlighted that the absence of hostile parenting patterns and parental wellbeing plays an important role in maintaining the children's social and emotional wellbeing. (Parsons 2020) Therefore, the investigation of parental responses to the challenges might contribute to a better understanding of the children's psychological state too. For the descriptive statistics of the studies mentioned here, see Table 2.

Chinese preliminary research found that children were more likely to show inattention, irritability, clinging, and persistent inquiry. The rates of fear, anxiety, and other emotions were higher in children residing in highly epidemic areas; however, the differences between areas identified by different levels of epidemic risk were not statistically significant. (Jiao et al 2020) Children seem more likely to develop symptoms of depression and anxiety (Xinjan et al 2020) and are also more likely to experience regression, fear, irritability, and sudden changes in mood than they were before the COVID-19 pandemic (Pisano et al 2020).

\begin{tabular}{|c|c|c|c|}
\hline $\begin{array}{l}\text { parent } \\
\text { population }\end{array}$ & children's age & surveys & source \\
\hline $\mathrm{N}=183$ & under 18 & COVID-19 risks, General Anxiety & Brown et al \\
\hline Mage $=$ & & Disorder-7, Parent-Child & 2020 \\
\hline $35.37 \pm 7.30$ & & Relationship Inventory, & \\
\hline female: & & Perceived Stress Scale, & \\
\hline $89,6 \%$ & & Perceived Control Over Stressful & \\
\hline & & $\begin{array}{l}\text { Events Scale, Cognitive Emotion } \\
\text { Regulation Ouestionnaire }\end{array}$ & \\
\hline$N=1114$ & & sociodemographics of parents & Orgiles et al \\
\hline Mage $=$ & Mage $=$ & and children, parental & 2020 \\
\hline $42.3 \pm 6.17$ & $9.08 \pm 4.22$ & perception on how quarantine & \\
\hline female: & & emotionally affects children & \\
\hline $47,5 \%$ & & $\begin{array}{l}\text { through } 31 \text { symptoms ranging } \\
\text { from } 1 \text { (much less compared to }\end{array}$ & \\
\hline
\end{tabular}




$\begin{array}{ll} & \text { before quarantine) to } 5 \text { (much } \\ & \text { more compared to before } \\ & \text { quarantine), parent's perception } \\ & \text { of family coexistence during } \\ \text { quarantine, the severity of the } & \\ & \text { situation caused by coronavirus } \\ & \text { for the family well-being, and } \\ & \text { parents stress, on a five-point } \\ & \text { scale, and children routines: } \\ & \text { time of screen use, physical } \\ & \text { activity, and hours of sleep } \\ & \text { during quarantine compared to } \\ \text { N }=854 & \text { before } \\ \text { female: } 797 & \text { Mage }=7.14 \pm 3.38 \text { Home Environment Risk Index } \\ \text { mothers: } & \text { (ad hoc); Quarantine Parent } \\ \text { Mage }= & \text { Risk Index; Parenting-Stress } \\ 38.96 \pm 6.02 & \text { Index Short Form (PSI); } \\ \text { fathers } & \text { Depression Anxiety Strss Scale, } \\ \text { Mage }= & \text { DASS;Strengths and Difficulties } \\ 41.9 \pm 6.75 & \text { Questionnaire (SDQ) } \\ & \end{array}$

Table 2: Descriptive statistics of some major research with a focus on the parental perception

In an Italian Spanish comparative study, only $11,4 \%$ of the children perceived family coexistence during the quarantine difficult or very difficult. On the other hand, approximately one-third of the parents reported being stressed or very stressed. Those parents who perceived themselves as more stressed tended to report that their children were more worried, anxious, uneasy, and reluctant. They also experienced that their children cry more and have difficulty with sleeping alone. Unexpectedly, no differences were observed in how serious the current situation caused by the coronavirus is for their well-being and the level of parental stress. (Orgilés et al 2020)

The role of parental perception of difficulties is demonstrated in other studies too. This perception seems to be a pivotal factor in both the children's and parents' wellbeing as the impact of the quarantine' on children's behavioral and emotional problems is mediated by parent's individual and dyadic stress, with a stronger effect from the latter. Parents who reported more difficulties in dealing with quarantine show more stress. (Spinelli et al 2020) High anxiety and depressive symptoms are correlated with higher parental perceived stress which raises the 
prevalence of child abuse. However, findings suggest that although families experience stressors from COVID-19, providing parental support and increasing perceived control may be promising in an intervention. (Brown et al 2020)

The inner psychological mechanisms beyond successful adaptation were explored by a study of Pisano (Pisano et al. 2020) Despite the fact that the majority of the children ( $92 \%$ ) seemed able to adapt to the restrictions, half of them showed increased irritability, intolerance to rules and excessive demands. Regressive symptoms could be also recorded and many withdrew from activities they were undertaking before the pandemic. 942 out of 5543 children manifested fears that they did not display before. So, distress can be detectible even in their cases. (Pisano et al 2020)

\section{(3) Research examining family system}

The structure of families (individuals, dyads, whole families) seem to function as key mediating effects in modifying risk emanating to the individual (Prime et al 2020) Despite the fact that the importance of this approach is articulated by some experts the amount of such research is still relatively low. In a Hungarian online research perceived stress level, resilience, and well-being of 346 adolescent-parent dyads were examined. The level of perceived stress was high. A surprising finding was that the parent's resilience directly reduced their child's well-being. However, a higher level of parental wellbeing (that is affected by their resilience) altogether leads to a higher level of well-being among the children too. (Csikós et al 2020)

\section{Conclusion}

The aforementioned studies emphasize the importance of parents coping with the challenges created by the pandemics. Relaxation techniques could be useful tools for decreasing stress and preventing depression. Methods of cognitive-behavior therapy also seem to be applicable in managing stress and reducing maladaptive coping mechanisms like avoidance or self-accusation. However, the effectiveness of personal resilience seems to be fragile in these exceptional times (Ho et al 2020) Adolescents are even more vulnerable and require careful consideration by caregivers and the social system for mental health support. Research on adolescent psychiatric disorders is also necessary, as such a global situation could be prolonged or repeated. (Guessoum, et al 2020, (Racine et al 2020) So, health systems and the social sector should also be prepared both for helping adolescents and family structures by free counseling (Sharma et al 2020)

\section{Acknowledgments}

This research was financed by Károli Gáspár University of the Reformed Church. 


\section{References}

[1] Andrews Jack L Lucy Foulkes Sarah-Jayne Blakemore: Peer Influence in Adolescence: Public-Health Implications for COVID-19 Trends in Cognitive Sciences Volume 24, Issue 8, August 2020, Pages 585-587

[2] Brown SM, Doom JR, Lechuga-Pẽna S, Watamura SE, Koppels T, Stress and Parenting during the Global COVID-19 Pandemic, Child Abuse and amp; Neglect (2020), doi:https://doi.org/10.1016/j.chiabu.2020.104699

[3] Bruining, H., Bartels, M., Polderman, T.J.C. et al. COVID-19 and child and adolescent psychiatry: an unexpected blessing for part of our population?. Eur Child Adolesc Psychiatry (2020). https://doi.org/10.1007/s00787-02001578-5

[4] Campbell Andrew M 2020: An increasing risk of family violence during the Covid-19 pandemic: Strengthening community collaborations to save lives. Forensic Science International: Reports. Volume 2, December 2020 https://doi.org/10.1016/j.fsir.2020.100089

[5] Csikós, Gábor; Törő, Krisztina; Rózsa, Sándor; Hadházi, Éva; Kövesdi, Andrea; Földi, Rita 2020: Psychological factors in Hungarian families under the coronavirus pandemic: The effects of resilience and stress on the wellbeing of adolescents, their interconnections within the family In Alison, Taysum; Siavash, Bakhtiar; Sophio, Moralishvili; Ahmet, Ecirli (eds) ICMS XXIII Proceedings Book Volume 1: 23rd International Conference on Multidisciplinary Studies: "Resilience for Survival" European Center for Science Education and Research (EUSER) pp. 11-18

[6] Dalton Louise - Rapa Elizabeth - Stein Alan: Protecting the psychological health of children through effective communication about COVID-19. The Lancet Child \& Adolescent Health VOLUME 4, ISSUE 5, P346-347, MAY 01, 2020

[7] Davis, Courtney; Ng, Kee Chong; Oh, Jean Yin; Baeg, Amerie; Rajasegaran, Kumudhini; Chew, Chu Shan Elaine (2020): Caring for Children and Adolescents With Eating Disorders in the Current Coronavirus 19 Pandemic: A Singapore Perspective. J Adolesc Health ; 67(1): 131-134

[8] Dubey Souvik - PayelBiswasbRitwikGhoshcSubhankarChatterjeedMahua JanaDubeyeSubhamChatterjeefDurjoyLahirigCarl J.Lavieh 2020:

Psychosocial impact of COVID-19. Diabetes \& Metabolic Syndrome: Clinical Research \& Reviews Volume 14, Issue 5, September-October 2020, Pages 779-788

[9] Dvorsky, M.R., Breaux, R. \& Becker, S.P. Finding ordinary magic in extraordinary times: child and adolescent resilience during the COVID-19 pandemic. Eur Child Adolesc Psychiatry (2020). https://doi.org/10.1007/s00787-020-01583-8 
[10] Ellis, W. E., Dumas, T. M., \& Forbes, L. M. (2020). Physically isolated but socially connected: Psychological adjustment and stress among adolescents during the initial COVID-19 crisis. Canadian Journal of Behavioural Science / Revue Canadienne des sciences du comportement, 52(3), 177-187. http://dx.doi.org/10.1037/cbs0000215

[11] Elmer T, Mepham K, Stadtfeld C. Students under lockdown: comparisons of students' social networks and mental health before and during the COVID-19 crisis in Switzerland. PLoS ONE. (2020) 15:e0236337. 10.1371/journal.pone.0236337

[12] Ghosh, Ritwik - Dubey, Mahua - Chatterjee, Subhankar - Dubey, Souvik: Impact of COVID-19 on children: Special focus on psychosocial aspect. Minerva Pediatrica 72(3):226-235 DOI: 10.23736/S0026-4946.20.05887-9

[13] Goldman Philip S - Marinus Hvan IjzendoornbEdmund J SSonuga-Barkec 2020: The implications of COVID-19 for the care of children living in residential institutions The Lancet Child \& Adolescent Health. Volume 4, Issue 6, June 2020, Page e12

[14] Guessoum, S. B., Lachal, J., Radjack, R., Carretier, E., Minassian, S., Benoit, L., \& Moro, M. R. (2020). Adolescent psychiatric disorders during the COVID-19 pandemic and lockdown. Psychiatry Research, 291, 113264. https://doi.org/10.1016/j.psychres.2020.113264

[15] Ho CS, Chee CY, Ho RC. Mental Health Strategies to Combat the Psychological Impact of COVID-19 Beyond Paranoia and Panic. Ann Acad Med Singap. 2020 Mar 16;49(3):155-160. PMID: 32200399.

[16] Huebener Mathias \& Waights Sevrin \& Spiess C. Katharina \&. Siegel Nico A \&. Wagner, Gert G (2020). "Parental Well-Being in Times of Covid-19 in Germany," CESifo Working Paper Series 8487, CESifo.

[17] Idoiaga N., Berasategi N., Eiguren A., Picaza M. (2020). Exploring children's social and emotional representations of the Covid-19 pandemic. Front. Psychol. 11:1952. 10.3389/fpsyg.2020.01952

[18] Jiao WY, Wang LN, Liu J, Fang SF, Jiao FY, Pettoello-Mantovani M, et al. Behavioral and Emotional Disorders in Children during the COVID-19 Epidemic. J Pediatr. 2020;221:264-6.e1

[19] Király, Orsolya; Potenza, Marc N.; Stein, Dan J.; King, Daniel L.; Hodgins, David C.; Demetrovics, Zsolt (2020) Preventing problematic internet use during the COVID-19 pandemic: Consensus guidance. COMPREHENSIVE PSYCHIATRY, 100. pp. 1-4. ISSN 0010-440X

[20] Lee 2020: Mental health effects of school closures during COVID-19 The Lancet Child \& Adolescent Health Volume 4, Issue 6, June 2020, Page 421

[21] Liu Jia Jia - Yanping Bao - Xiaolin Huang Je Shi 2020: Mental health considerations for children quarantined because of COVID-19. The Lancet. Child and Adolescent Health. VOLUME 4, ISSUE 5, P347-349, MAY 01, 2020 
[22] Oosterhoff, B., Palmer, C., Wilson, J., \& Shook, N. (2020, April 6). Adolescents' Motivations to Engage in Social Distancing during the COVID-19 Pandemic: Associations with Mental and Social Health. https://doi.org/10.31234/osf.io/jd2kq

[23] Orgilés, Mireia, Alexandra Morales, Elisa Delvecchio, Claudia Mazzeschi, and José P. Espada. 2020. "Immediate Psychological Effects of the COVID-19 Quarantine in Youth from Italy and Spain." PsyArXiv. April 21. doi:10.31234/osf.io/5bpfz.

[24] Parsons J. (2020): COVID-19, kids, and anxiety in 2020. Aust J Gen Pract 2020;49 Suppl 27. DOI: 10.31128/AJGP-COVID-27.

[25] Pisano, Luca, Domenico Galimi, and Luca Cerniglia. 2020. "A Qualitative Report on Exploratory Data on the Possible Emotional/behavioral Correlates of Covid-19 Lockdown in 4-10 Years Children in Italy." PsyArXiv. April 13. doi:10.31234/osfio/stwbn.

[26] Prime, H., Wade, M., \& Browne, D. T. (2020). Risk and resilience in family well-being during the COVID-19 pandemic. American Psychologist, 75(5), 631-643. http://dx.doi.org/10.1037/amp0000660

[27] Racine, N., Cooke, J. E., Eirich, R., Korczak, D. J., McArthur, B., \& Madigan, S. (2020). Child and adolescent mental illness during COVID-19: A rapid review. Psychiatry Research, 292, 113307. https://doi.org/10.1016/j.psychres.2020.113307

[28] Remmerswaal D, Muris P. Children's fear reactions to the 2009 Swine Flu pandemic: the role of threat information as provided by parents. J Anxiety Disord. 2011 Apr;25(3):444-9. DOI: 10.1016/j.janxdis.2010.11.008. Epub 2010 Nov 19. PMID: 21159486.

[29] Sharma Vinita Ph.D., M.P.H.MiguelReina OrtizM.D., Ph.D., C.P.H.NanditaSharmaPh.D.: Risk and Protective Factors for Adolescent and Young Adult Mental Health Within the Context of COVID-19: A Perspective From Nepal Journal of Adolescent Health Volume 67, Issue 1, July 2020, Pages 135-137

[30] Spinelli Maria, Lionetti Francesca, Pastora Massimiliano, Fasolo, Mirco 2020: Parents' Stress and Children's Psychological Problems in Families Facing the COVID-19 Outbreak in Italy Frontiers in Psychology, | https://doi.org/10.3389/fpsyg.2020.01713

[31] Usher, K., Bhullar, N., Durkin, J., Gyamfi, N., Jackson, D. (2020). Family violence and COVID-19: Increased vulnerability and reduced options for support. International Journal of Mental Health Nursing. https://doi.org/10.1111/inm.12735

[32] Xinyan Xie, Qi Xue, Yu Zhou, et al. 2020: Mental Health Status Among Children in Home Confinement During the Coronavirus Disease 2019 Outbreak in Hubei Province, China. Jama Pediatrics. 
[33] Zhou, X. (2020). Managing psychological distress in children and adolescents following the COVID-19 epidemic: A cooperative approach. Psychological Trauma: Theory, Research, Practice, and Policy, 12(S1), S76-S78. http://dx.doi.org/10.1037/tra0000754 